\title{
Linguagem e letramento: construindo novos sentidos
}

\author{
Ana Paula Loureiro \\ Colégio Santo Inácio
}

\begin{abstract}
Resumo
Este artigo tem por objetivo discutir o letramento como prática social. Para isso, lanço mão das teorias linguísticas de Bakhtin (2004) que embasam uma visão dialógica da linguagem e a compreensão do letramento como prática social. Esses sentidos parecem problematizar a visão de linguagem tradicional. Argumento, também, que a teorização de Bakhtin apresenta implicações para a revisão da noção de letramento ainda norteadora de práticas pedagógicas em sala de aula.

Palavras-chave: linguagem, letramento, prática social, dialogismo
\end{abstract}

\begin{abstract}
In this paper my intent is to discuss literacy as a social practice. So as to reach this objective, I make use of Bakhtin's (2004) linguistic theories which constitute the basis of a dialogical view of language and the understanding of literacy as a social practice. These meanings seem to problematize the traditional view of language. I argue that Bakhin's theoretical ideas can contribute to reviewing the approach to literacy that still reigns over pedagogical practices.

Keywords: language, literacy, social practice, dialogism
\end{abstract}

\section{INTRODUÇÃO}

Leciono Inglês desde 1989, quando terminei a graduação em Letras. Desde então, vinha percebendo que minha formação docente, ainda calcada no paradigma da transmissão e respondendo a uma ordem disciplinar e pan-óptica, parecia nortear minha prática. Isso me fez pensar que, em pleno século XXI, minhas aulas poderiam estar em dissonância em relação a um mundo marcado por mudanças radicais. A decisão de voltar a estudar e ingressar no curso de mestrado foi motivada, portanto, por uma necessidade de reflexão sobre minha própria prática, que, a meu ver, já parecia um tanto inadequada diante dos desafios e demandas impostos pela contemporaneidade.

Ao iniciar o curso, tive acesso a teorizações que começaram a influenciar minha visão de linguagem e aprendizagem. Entrei em contato com uma concepção linguística que se afasta de uma visão essencialista e representacionista. Ao recorrer ao filósofo da 
linguagem Bakhtin (2004), passei a entender que a linguagem não representa o mundo social, mas o constrói na trama das relações sociais. Dessa forma, compreendi que a linguagem é construtora dos sentidos produzidos sobre a realidade e sobre quem somos (LARROSA,2002).

Essa noção me foi muito importante para perceber que a realidade não existe independentemente do sujeito social que a cria e descreve. Se a própria realidade é socialmente construída, põe-se em xeque a objetividade e a neutralidade do conhecimento defendida pelo positivismo (SEMPRINI, 1999). O conhecimento passa a ser visto, então, como "uma versão da realidade" (Ibid., p. 84). Isso me levou a pensar que o mundo social e o conhecimento que sobre ele produzimos são frutos de intercâmbios interpessoais (SPINK, 1997). Uma vez que não se compreende o conhecimento como algo externo a ser assimilado pelo sujeito, reforça-se a concepção de que o saber é sempre construído na relação com o outro. Associada a essa perspectiva, minha visão de aprendizagem passou a se voltar para a dimensão intersubjetiva; o que não reduz o processo de ensino-aprendizagem à mera transmissão.

Cabe destacar também o próprio conceito de letramento, até então desconhecido por mim. Ao considerarmos que a linguagem não é um fenômeno social, mas um sistema abstrato e fixo, a comunicação é entendida como um processo de simples codificação-decodificação de textos (PENNYCOOK, 2001), ou seja, a leitura envolve a relação individual do leitor com o texto para decodificar símbolos e apreender significados. Entretanto, ao conceber a linguagem como prática social e não como sistema linguístico, Bakhtin (2004) considera que os significados não são propriedades de textos fixos e estáveis. Ler um texto é, portanto, um processo social que não se limita a transmitir ideias de um autor para um leitor (BLOOME, 1983).

Foi assim que dei início à reflexão crítica sobre minha prática docente. Afinal de contas, o professor que não interroga sobre si próprio e ignora as transformações no mundo que o rodeia não se transforma e tende a se estagnar, afastando-se da dinâmica contemporânea marcada por instabilidade, mudança constante e flexibilidade. É o processo de experimentação, reflexão e diálogo que pode ajudar o docente e a escola a repensarem e recriarem os saberes escolares, o currículo e a própria pedagogia, de forma que escola e mundo social se aproximem. Neste artigo, busco propor uma reflexão sobre o conceito de letramento, destacando como ele passa a ser visto como 
prática social. Inicialmente, discuto a perspectiva linguística tradicional que fundamenta uma visão de linguagem meramente expressiva e monológica. Visando problematizar tais sentidos, recorro, depois, à teorização de Bakhtin e suas implicações para a visão de letramento valorizada na escola. Em seguida, descrevo o conceito de letramento como prática social. Finalizo comentando como essas noções ajudam a desestabilizar ideias naturalizadas de Educação.

\section{PERSPECTIVA LINGUÍSTICA TRADICIONAL}

Como bem sinaliza Freitas (1995), a epistemologia das Ciências Humanas e Sociais, influenciada pelo positivismo das Ciências Naturais, reduzia o ser humano a seus aspectos biológicos, ao mesmo tempo em que o Estruturalismo desvinculava a língua de seu contexto real, para tratá-la como um sistema abstrato de formas e regras. Stam (2000) destaca que Saussure, já no início do século XX, colocou-se a favor de uma abordagem sincrônica da linguagem. Seu estudo pressupunha a segmentação em unidades fônicas - fonema e sílaba - e/ou unidades significantes - palavra e oração. Ainda, segundo Stam (Ibid), a linguagem, dentro da tradição de Saussure na Linguística Estrutural, limitava-se a categorias fonéticas e morfológicas. Auroux (1998) salienta que a Linguística mantém-se até o final dos anos 50 calcada nessa metodologia denominada Estruturalismo. Com base nessa perspectiva, a linguagem era vista "como um sistema sincrônico estático" (STAM, 2000, p.32), apresentando-se, portanto, como algo completo e acabado. Assim sendo, não haveria espaço para negociação de significados entre os falantes. É aqui que percebemos a função monológica da linguagem que posiciona as formas linguísticas acima da própria comunicação. Esses princípios atendem a uma visão de linguagem, de sujeito, de mundo social, de conhecimento e de ensino-aprendizagem que remontam a uma epistemologia definida por Semprini (1999) como monocultural. De acordo com essa posição epistemológica, o mundo social independe das representações mentais e linguísticas que fazemos da realidade. Isso significa dizer que cabe à linguagem apenas descrever e representar esse mundo. Ou seja, já existe um mundo pré-discursivo, restando à linguagem descrevê-lo e reproduzi-lo. A linguagem reduz-se, então, a codificar entidades dotadas de existência própria. Linguagem e realidade são entendidas, portanto, como domínios separados. 
Entende-se que os sentidos nos são dados a priori, pois os significados são vistos como propriedades intrínsecas a pessoas e coisas.

Essa concepção supõe que os sentidos sejam considerados qualidades reais, tidas como dadas, definitivas e fixas, o que sustenta a crença na existência de uma identidade única para pessoas e objetos. Sob a influência dessa crença, o ideal humanista defendeu a ideia de que o sujeito é homogêneo, centrado e coeso. Portanto, a identidade social é pensada como dada e vista como algo permanente e imóvel.

Essa noção de que conceitos e identidades são simplesmente descritos e representados pela linguagem constrói a ideia de que os sentidos não são produzidos intersubjetivamente. Ou seja, a relação com os significados é encarada como situada acima das relações sociais. De fato, a linguagem desvincula-se de um contexto social para ser encarada como um modelo abstrato de formas e regras que compõem um sistema pronto e estável. Ora, se a linguagem está dissociada das relações intersubjetivas, não se pode considerar seu envolvimento com questões culturais ou ideológicas. Isso nos faz compreender que o uso da linguagem é neutro, autônomo e independente de um contexto socio-histórico.

Ao se acreditar que a linguagem não é um fenômeno social, não se pode crer que os sentidos sejam fruto de uma coconstrução. Ao contrário, supõe-se que esses sentidos são apenas transmitidos. De acordo com essa visão de linguagem, a compreensão do processo de ensino-aprendizagem reduz-se à mera transmissão, pois se entende que o mestre deve transmitir aos alunos os sentidos a serem por eles absorvidos e reproduzidos, excluindo a negociação e a construção colaborativa. Nesse paradigma, o acúmulo de conteúdos valoriza mais a imposição de sentidos do que a negociação intersubjetiva. Portanto, a aprendizagem muitas vezes se resume apenas à simples memorização de informações.

Ora, se os significados são autônomos e preestabelecidos, visto que são atribuídos a propriedades intrínsecas a pessoas e objetos, não podemos abrir espaços para a criação de novos sentidos e operar transformações. Ficaríamos, então, aprisionados a um mundo pré-linguagem e determinista. $\mathrm{E}$, se a linguagem é um sistema abstrato e fixo, a comunicação é entendida como um movimento de emissão-recepção e um processo de codificação-decodificação de significados. Além disso, se os significados se 
fundamentam em princípios naturais ou essenciais, excluem-se, assim, as contingências socio-históricas.

Tal posição epistemológica monocultural (SEMPRINI,1999), como o próprio nome sugere, valoriza uma única cultura hegemônica que focaliza o pensamento ocidental, impondo-nos um olhar que enxerga o mundo compreendido como um cenário homogêneo, no qual a diversidade e a pluralidade são ignoradas. Com o intuito de pôr em xeque os sentidos atribuídos à linguagem, apresentarei, a seguir, as contribuições do filósofo Bakhtin.

\section{UMA VISÃO DIALÓGICA DE LINGUAGEM}

As teorias de Bakhtin opuseram-se à perspectiva linguística tradicional que postula a linguagem como se fosse um sistema estável e abstrato de elementos linguísticos. Esse sistema - fechado e imutável - é visto como objetivo e dissociado de variações sociais do próprio contexto de comunicação. Esses elementos preexistem ao indivíduo, a quem cabe, então, reproduzi-los. Entretanto, para Bakhtin, a linguagem não é um sistema fechado e acabado; ao contrário, está em processo contínuo de transformação sob as influências do próprio uso cotidiano em nossas interações. Os elementos linguísticos são, portanto, produzidos em contextos sociais. Assim, a linguagem passa a ser vista como mutável, ou seja, sempre aberta a novos significados em cada novo contexto.

De fato, Bakhtin não compreendia a linguagem fora de seu contexto sociohistórico, estabelecendo ligação inseparável entre eles. Uma vez que a linguagem só pode ser entendida dentro de um contexto, é inevitável que esteja sujeita às contingências sociais, culturais e ideológicas. Ele chega mesmo a considerar a palavra como um "fenômeno ideológico" (BAKHTIN, 2004, p. 36).

O termo ideologia é empregado por esse filósofo, de acordo com Freitas (1997, p. 319), para se referir "à maneira como os membros de um determinado grupo social veem o mundo". O que parece ficar claro é a importância do contexto prenhe de conteúdo ideológico - de valores e significados de um grupo situado sociohistoricamente - para a construção de significados. Por conta disso, Bakhtin (2004, p. 
95) afirma: "não são palavras o que pronunciamos ou escutamos, mas verdades ou mentiras, coisas boas ou más, importantes ou triviais, agradáveis ou desagradáveis".

Se a linguagem é profundamente social, ela permeia todas as relações intersubjetivas. De fato, Bakhtin alega que as palavras "servem de trama a todas as relações sociais em todos os domínios" (Ibid., p. 41). Ao se utilizar da metáfora da trama, ele alude ao fato de que as palavras são tecidas socialmente. Ora, como a linguagem é prática social, podemos concluir que ela seja fluida, isto é, aberta a constante movimento, pois é na trama de relações sociais que negociamos e propomos novos sentidos em contextos que nunca se repetem. Com efeito, "há tantas significações possíveis quantos contextos possíveis" (Ibid., p. 106). Portanto, há mobilidade na linguagem, que não se mantém aprisionada a significados estáveis e fixos.

A meu ver, ao encarar a linguagem como um fenômeno socio-histórico, Bakhtin tenta ressaltar a presença da alteridade como parte inalienável de nosso próprio discurso. Logo, é necessário fazer menção ao fato de que, para esse filósofo, a linguagem é sempre dialógica. Ao argumentar que a significação de uma palavra somente lhe pertence "enquanto traço de união entre os interlocutores, isto é, ela só se realiza no processo de compreensão ativa e responsiva" (BAKHTIN, 2004, p. 132), esse autor procura destacar que "a significação das palavras depende da relação entre sujeitos" (BARROS, 1996, p. 327). Isso significa dizer que "a relação com o sentido é sempre dialógica" (BAKHTIN, 2003, p. 327).

É com base nesse princípio dialógico que Bakhtin desenvolve o conceito denominado polifonia. Para ele,

A palavra não pode ser entregue apenas ao falante. $\mathrm{O}$ autor (falante) tem os seus direitos inalienáveis sobre a palavra, mas o ouvinte também tem os seus direitos; têm também os seus direitos aqueles cujas vozes estão na palavra encontrada de antemão pelo autor (porque não há palavra sem dono). (BAKHTIN, 2003, p. 328)

$\mathrm{Na}$ verdade, o que ele procura salientar é o fato de que as palavras estão impregnadas por múltiplas vozes sociais. Dessa forma, nosso discurso incorpora as palavras do outro, sendo este o nosso interlocutor mais próximo ou aqueles que estejam presentes na cultura. Nosso discurso reverbera, assim, as vozes da cultura. 
Em outros termos, é possível dizer que, em nossas práticas interacionais, ventriloquamos palavras dos outros que "trazem consigo a sua expressão, o seu tom valorativo que assimilamos, reelaboramos, e reacentuamos" (BAKHTIN, 2003, p. 295). Portanto, como afirma Bakhtin (Ibid., p. 294), "nosso discurso [...] é pleno de palavras dos outros".

Em estreita relação com esse conceito de polifonia, encontra-se o de intertextualidade. $\mathrm{O}$ dialogismo que fundamenta essa compreensão de discurso polifônico - de múltiplas vozes imbricadas - nos remete à noção de que todo texto também dialoga com outros textos (BRANDÃO, 1997). Há, portanto, um diálogo mais amplo entre textos. Acho relevante lembrar que, como o próprio filósofo diz, "cada palavra do texto o leva para além dos seus limites. Toda interpretação é o correlacionamento de dado texto com outros textos" (BAKHTIN, 2003, p. 400). Portanto, "compreender não é um ato passivo [...] mas uma réplica ativa, uma resposta" (FARACO, 2003, p. 42). É por conta dessa concepção de dialogismo que Barros (1996, p. 34) destaca que o texto pode ser compreendido "como um 'tecido de muitas vozes', ou de muitos textos ou discursos, que se entrecruzam [...] no interior do texto".

Assim sendo, não podemos nos ater somente ao diálogo autor-leitor. É claro que, ao escrever um texto, o escritor se preocupa com uma audiência projetada, para a qual orienta sua fala. Essa relação entre autor e leitor é entendida por Bakhtin como sendo necessariamente ativa. Ao invés de tentar encontrar os significados impostos por um autor, o leitor envolve-se ativamente ao construir sentidos em torno dos textos. Para Bakhtin (2004, p. 123), o livro é, na verdade, "objeto de discussões ativas sob a forma de diálogo e, além disso, é feito para ser apreendido de maneira ativa". Entretanto, esse diálogo mobiliza um repertório de sentidos que nos possibilita estabelecer também uma inter-relação entre múltiplos textos.

Já que na visão bakhtiniana a compreensão é sempre dialógica, cabe lembrar que "compreendemos as palavras e somente reagimos àquelas que despertam em nós ressonâncias ideológicas ou concernentes à vida" (Ibid., p. 95). Por conseguinte, a linguagem é capaz de nos fazer reagir a ela, produzindo efeitos sobre o(s) outro(s). Nesse sentido, é fundamental refletirmos sobre o que fazemos com a linguagem no mundo social e que sentidos, culturalmente disponibilizados, legitimamos em nossas 
práticas sociais cotidianas, pois, ao utilizarmos a linguagem, construímos sentidos de nós mesmos, de nossos interactantes, assim como do mundo, que podem ratificar crenças e valores sociais ou, então, problematizá-los. Daí emerge a questão de que a linguagem não se reduz a simplesmente representar o mundo social, pois, ao contrário, os significados construídos nas interações criam inteligibilidade sobre a realidade; logo, a linguagem constrói a vida social.

Em resumo, as ideias desse filósofo parecem desestabilizar o papel representacionista da linguagem, pondo em xeque a crença de que os significados são intrínsecos às palavras e, portanto, autônomos. Para Bakhtin, os significados são coconstruídos nas interações, isto é, utilizando a linguagem em nossas interações ações intersubjetivas - cotidianas, situadas em determinado contexto socio-histórico. Tomando por base essa perspectiva linguística não representacionista, podemos, então, compreender que a linguagem não apenas reflete a realidade, mas a constrói semanticamente na trama das relações intersubjetivas.

É, portanto, nas práticas discursivas que coproduzimos sentidos e coconstruímos também nossas subjetividades. Dessa forma, os significados e o sujeito social são frutos de uma produção discursiva que envolve necessariamente a alteridade e a situacionalidade. Fica também claro que as práticas discursivas nas quais nos engajamos não são a-históricas, pois estão sempre situadas em um contexto social. Nas várias práticas sociais pelas quais circulamos, nós nos construímos, mas também construímos nossos interlocutores. Ganham relevância, assim, os planos relacional, situacional e histórico implicados na construção de inteligibilidade sobre o mundo social e sobre quem somos por meio da linguagem. A meu ver, esse "olhar" sobre a linguagem entrelaça mundo social, processos linguísticos e processos subjetivos. Se a linguagem age sobre o mundo e o sujeito, seu papel não pode ser limitado à função representacional - o que nos sugere que o mundo social e o sujeito são construções discursivas.

Essa visão dialógica da linguagem desenvolvida por Bakhtin desconstrói a crença de que existe algo exterior à própria linguagem, ao mesmo tempo em que desestabiliza o princípio de que os significados são como propriedades intrínsecas a objetos e a pessoas. A relação com o significado é sempre intersubjetiva, ou seja, os significados 
não são entidades autônomas, dotadas de uma identidade essencial. Portanto, os significados não nos são dados, mas negociados em nossas relações sociais, situadas em um contexto socio-histórico. Em suma, não há uma "entidade" externa da qual a linguagem seria mera representação.

Tal perspectiva tem implicações para a visão de letramento que parece ser valorizada na escola, pondo em xeque um modelo que atribui significados aos textos, excluindo o contexto social de construção de sentidos. Segundo a visão linguística bakhtiniana, o letramento passa a ser compreendido como prática social, intersubjetiva e situada. A seguir, discutirei tal noção.

\section{VISÃO DE LETRAMENTO COMO PRÁTICA SOCIAL}

O termo letramento (KLEIMAN, 1995) foi inserido na Educação e nas Ciências Linguísticas na segunda metade dos anos 80 (SOARES, 2004). O emprego dessa nova expressão teria sido desencadeado pela tentativa de separar os estudos sobre alfabetização dos estudos voltados para o impacto social da escrita (KLEIMAN, 1995). O que está em jogo, portanto, não é apenas o ler e escrever, mas também o fazer uso do ler e do escrever, atendendo às demandas de leitura e de escrita que a própria sociedade nos impõe. Assim, ser letrado implica "envolver-se nas práticas sociais de leitura e de escrita" (SOARES, 2004, p. 36).

Com o intuito de melhor compreender o que seja letramento, é fundamental deixar claro que existem duas dimensões principais envolvidas: a dimensão individual e a dimensão social (SOARES, 2004). A dimensão individual do letramento é mais bem compreendida quando pensamos na escola. Nessa instituição, uma agência de letramento tão importante, valoriza-se somente um tipo de prática, a alfabetização, como mero processo de aquisição de códigos, geralmente entendido em termos de competência individual (KLEIMAN, 1995). Dessa forma, nota-se a ênfase dada às habilidades cognitivas e linguísticas - especialmente a que se refere à decodificação de símbolos e códigos - e, portanto, restritas ao próprio indivíduo.

Essa dimensão individual parece dialogar com um dos modelos de letramento propostos por Street (1995). Conforme esse autor, haveria um modelo autônomo de 
letramento dissociado do contexto sociocultural e voltado para os aspectos técnicos. Por esse motivo, tal modelo privilegia pressupostos teóricos que subjazem uma visão sistêmica da língua que se intitula "neutra", ou seja, acima das relações de poder. Logo, infere-se que tal modelo se afina com a dimensão individual do letramento por priorizar aspectos cognitivos e técnicos do indivíduo.

A escola, como já citado, ainda parece limitar-se ao modelo autônomo e individual de letramento, excluindo aspectos contextuais e sociais (KLEIMAN, 1995). Consequentemente, o letramento escolar não é visto como troca entre sujeitos situados em um contexto. Portanto, a escola, observa Kleiman (Ibid., p. 45), "pressupõe uma separação polarizada entre a oralidade e a escrita". Street (1995) destaca que, subjacente a essa divisão, encontra-se um dos mitos do letramento criado pela Linguística Tradicional, que pressupunha a autonomia da linguagem escrita, isto é, os significados seriam intrínsecos ao próprio texto. Moita Lopes (1996, p. 2) concorda com essa posição ao afirmar que a escola "opera com uma visão logocêntrica do significado, em que a função do leitor é decodificar o significado do texto ou a intenção do autor”.

Em sintonia com esses pressupostos, Bloome (1983, p. 165) observa que: "A leitura é vista como um processo cognitivo de decodificação de símbolos impressos para se obter significados. O foco está, então, na relação entre escritor e leitor." De fato, no modelo autônomo de letramento, a leitura reduz-se à relação individual do leitor com o texto. Pressupõe-se um processo basicamente cognitivo que envolve decodificar símbolos para apreender os significados atribuídos aos textos.

Ao ponderar que a escola ainda privilegia um modelo de letramento autônomo, Kleiman (1995, p. 22) esclarece que tal "autonomia refere-se ao fato de que a escrita seria [...] um modelo completo em si mesmo". O que me parece crucial considerar agora é a visão de linguagem que fundamenta esse modelo de letramento. Para isso, é indispensável lembrar que, ao se encarar a língua como um sistema abstrato de normas e regras, os significados aparecem como propriedades intrínsecas a objetos e pessoas. Logo, à linguagem cabe apenas representar e refletir o mundo social. Com isso, passa-se a supor que as palavras "carregam" significados fechados em si mesmos e, portanto, tidos como fixos e estáveis. Ou seja, o modelo autônomo de letramento ancora-se em 
uma visão de linguagem como sistema de códigos, independente de aspectos sociais e contextuais, e cuja função é representacionista.

Em oposição a esse modelo, muitos entendem o letramento como prática social. Para Soares (2004, p.72), "letramento é o que as pessoas fazem com as habilidades de leitura e de escrita, em um contexto específico, e como essas habilidades se relacionam com as necessidades, valores e práticas sociais." A dimensão social do letramento, diferentemente da dimensão individual, sintoniza-se com o que Street (1995) chamou de modelo ideológico. Nesse modelo, os aspectos técnicos e cognitivos de ler e escrever não são negados, porém estão inseridos em estruturas sociais e culturais; logo, encontram-se ligados à questão de poder e ideologia. Ora, dessa forma, o letramento não pode ser dissociado dos contextos e instituições sociais, ou seja, o que é feito com o letramento está sujeito às contingências sociais, históricas, culturais e ideológicas.

Mais uma vez, é preciso refletir sobre as premissas em relação à linguagem que subjazem a esse modelo. Nesse sentido, recorro novamente ao filósofo Bakhtin, cujas ideias desestabilizam a visão representacionista da linguagem para salientar a perspectiva social da construção dos sentidos. Assim, os sentidos são construídos na trama das relações sociais, ou seja, no diálogo com o outro, como nos aponta Bakhtin. Com efeito, não se pode pensar em linguagem fora do âmbito da alteridade. $\mathrm{O}$ mundo dos sentidos não se encontra fechado, nem preestabelecido. Ao contrário, está sempre aberto ao processo constante de negociação intersubjetiva nos variados contextos de comunicação. Podemos, então, afirmar que esses significados não são estáticos, mas móveis e sujeitos às contingências sociais e culturais, pois são produzidos dentro de um contexto situado socio-historicamente. O modelo ideológico de letramento fundamentase nessa concepção de linguagem como prática social, isto é, posicionada no âmbito das relações interpessoais.

Bloome (1993) ressalta a importância dessas relações interpessoais em um evento de leitura. Ao pôr em xeque a concepção de que o leitor busca obter o significado imposto pelo autor de um texto, ele se alinha a Bakhtin, que defendia a existência de uma relação ativa entre autor e leitor. Bloome também enfatiza a necessidade de se ver a leitura como um processo social que transcende o modelo de decodificação, não se resumindo a transmitir ideias de um autor para um leitor. 
A leitura passa a ser vista como estando aberta à constante reinterpretação e recriação, processo também sinalizado por Maybin e Moss (1993, p. 144) ao afirmarem: “As leituras nunca estão fechadas. Estão continuamente feitas e refeitas na conversa sobre o texto." Isso significa dizer que construímos sentidos em torno do texto. Ao tentar compreender esse texto, nós o reconstruímos e o recriamos com nossas próprias palavras. Ao conversarmos sobre o texto, reelaboramos os significados que são construídos colaborativa e provisoriamente. Assim, o texto é refeito, num embate que envolve diferentes interpretações. Se os significados emergem nas negociações entre os participantes de uma prática de letramento, desestabiliza-se a ideia de que o significado é intrínseco ao texto e, portanto, estático e pré-definido - reduzindo o texto a uma única leitura possível. Dessa forma, a leitura é vista como um processo social que envolve não só a interação autor-leitor, mas também as relações sociais entre pessoas durante um evento de leitura. Em outras palavras, a leitura é compreendida como um evento sociocultural que envolve a língua escrita, fundamentando-se na negociação e construção colaborativa de sentidos (BLOOME, 1993). As palavras de Bakhtin (2004, p. 113) resumem a visão de linguagem implicada em tal perspectiva: "A palavra é uma espécie de ponte lançada entre mim e os outros. Se ela se apoia sobre mim numa extremidade, na outra apoia-se sobre meu interlocutor."

Antes de prosseguir, é relevante reiterar que, no modelo ideológico, as práticas de letramento são determinadas social e culturalmente (KLEIMAN, 1995). Assim, há ainda que se levar em conta a situacionalidade do letramento. Essa ideia é muito bem expressa por Moita Lopes (1996, p. 1) ao enfatizar: “Os significados construídos por leitores refletem o contexto social imediato, no qual estão localizados, como também, o mundo social mais amplo no qual estes contextos estão situados.” Em outras palavras, em nossas práticas discursivas, estamos a todo momento recuperando sentidos que nos são disponibilizados publicamente nos discursos pelos quais circulamos, ou seja, tais sentidos carregam influências culturais e históricas.

Tal perspectiva pode ser aproximada da compreensão bakhtiniana de que todo discurso reverbera polifonicamente as vozes da cultura. É no âmbito das interações que nos apropriamos dos discursos - ventriloquamos essas vozes - para ratificá-los ou, então, para desconstruí-los. Acima de tudo, os significados que nós, leitores, produzimos não surgem a partir do nada, do inexistente, visto que os sentidos estão 
situados na inter-relação entre o contexto interacional e o contexto cultural-histórico mais abrangente. É nessa interface com o contexto cultural mais amplo que mobilizamos outros textos, construindo relações intertextuais que se referem à justaposição não só de textos escritos, mas também de textos orais; ou seja, em nossas práticas sociais de letramento, construímos relações intertextuais que acabam por produzir outro texto a partir do assunto discutido, com base em uma leitura (LEMKE, 1995). Ao considerar que os sentidos construídos estão sempre situados em um contexto social, histórico e cultural, Moita Lopes (2003) sugere que devemos atentar para as diversas escolhas feitas nas interações orais e escritas, sejam essas escolhas linguísticas, temáticas, textuais e de recursos semióticos, sempre situando as práticas discursivas.

Ao trazermos para a escola essa visão de letramento como prática social, passamos a compreender o letramento como práticas discursivas, isto é, como práticas de construção de significados. Assim, o letramento é um processo dinâmico, construído e reconstruído por sujeitos situados em determinado grupo social; portanto, como destacam Green et al. (1994, p. 146), “o letramento é realizado por meio de interações e comunicações de membros de um grupo.” Daí podermos ressaltar o fato de que os participantes em práticas de letramento "constroem e reconstroem significados sobre eles mesmos" (MOITA LOPES, 2005a, p. 49) e também sobre o mundo social. Não há dúvida, portanto, de que, ao nos engajarmos em práticas sociais de letramento, produzimos efeitos sobre os outros e, igualmente, sobre nós mesmos. E, aqui, não posso deixar de citar as palavras de Moita Lopes (Ibid., p. 50) para esclarecer que há "uma relação intrínseca entre letramentos e os processos de construção identitária”. Dito de outra forma, para esse autor, construímos nossas identidades nas diversas práticas de letramento nas quais nos engajamos, tanto na escola como fora dela. Assim sendo, ao construirmos sentidos intersubjetivamente em torno da leitura e da escrita, construímonos, mas também construímos nossos interlocutores. Dessa forma, não podemos ignorar os efeitos de subjetivação dessas práticas sociais.

A meu ver, esses sentidos atribuídos ao letramento como prática social, em sintonia com as teorias de Bakhtin, concebem a linguagem como um fenômeno social que permeia as relações interpessoais; portanto, a relação com o significado é sempre dialógica. Consequentemente, o sentido não está centrado na palavra. Supõe-se, então, que, como os significados não estão no texto, não é possível nos limitarmos a tentar 
decodificá-lo. Ao contrário, para compreendê-lo, precisamos construir, a partir desse texto, sentidos que são negociados intersubjetivamente. É nesse processo de troca entre sujeitos que construímos relações intertextuais com outros textos orais e escritos, ao mesmo tempo em que ventriloquamos polifonicamente as vozes culturais do contexto social mais amplo. Como em uma trama, os sentidos são, então, entretecidos no contato com alteridades em um movimento de entrecruzamento de várias culturas, o que contribui para uma ótica multicultural.

Como os significados construídos estão situados em um contexto social - sujeitos, portanto, às contingências socio-históricas -, nossa relação com a leitura e a escrita também é passível de sofrer essas influências contextuais. É nesse sentido que devemos refletir sobre o letramento dentro do cenário contemporâneo. Vivemos hoje sob um dilúvio informacional (LÉVY, 1999) e sob a onipresença da mídia (FRIDMAN, 2000). A comunicação já não se limita à modalidade da linguagem escrita e torna-se multimodal (KRESS, 2003). Temos acesso a uma enorme gama de discursos midiáticos, cada vez mais multissemiotizados, que nos expõe a "novas práticas sociais e a grupos e situações culturais muito diversos" (VEIGA-NETO, 2002, p. 181). Torna-se, portanto, cada vez mais difícil continuar imaginando nosso mundo como "um espaço social único, unitário e homogêneo" (Ibid., p. 178). Por essa razão, concordo com Soares (2004, p. 80), ao apontar o fato de que "novas demandas de comportamento letrado vão surgindo no contexto social". Como resultado, não devemos falar apenas de um só letramento (do texto impresso), mas de "multiletramentos" (COPE; KALANTZIS, 2000) - vários modos de produção de significados. Portanto, precisamos aprender a ser letrados em uma sociedade marcada pela mediação de textos hipersemiotizados da mídia.

De fato, por conta dos avanços tecnológicos, estamos expostos diariamente às redes de comunicação, especialmente à televisão e à internet, que nos oferecem, em tempo real, um mundo inteiro, flexibilizando nossa própria noção de tempo e espaço. Uma avalanche de discursos invade nossas vidas e nos apresenta uma heterogeneidade social que pode, até mesmo, desestabilizar nosso pensamento hegemônico, ao mostrar outras formas de sociabilidade (MOITA LOPES, 2005b). Por considerar que nossas visões de mundo e de sujeito podem ser, então, influenciadas por esses textos públicos da vida cotidiana, Luke (1997) dá ênfase à necessidade de se tratar a televisão como 
prática social. Isso se deve ao fato de que o letramento televisivo permeia nossas conversas, seja em família, no lazer, ou até no trabalho.

Além da televisão, o computador parece igualmente importante nesse cenário atual. Ao acessarmos os sites da internet, uma infinidade de discursos nos disponibiliza um repertório de sentidos que ora reforça os significados sociais, já naturalizados, ora parece problematizá-los, oferecendo outras possibilidades de agir, pensar e viver no mundo. As telas do computador não devem ser vistas como simples mediação entre o sujeito e o mundo social. Em lugar disso, utilizam-se múltiplas modalidades de comunicação - imagens, sons, cores, movimento - para construir sentidos sobre a vida social. Por conta disso, Moita Lopes (2005b) destaca a importância do computador não como máquina de escrever, mas atribuindo especial destaque ao seu potencial como local de construção de conhecimento. Ou seja, nossa interação com o computador pode ser considerada um tipo de letramento importante - letramento computacional -, que produz múltiplos significados. Esses significados podem atender a discursos hegemônicos que nos aprisionam a um ideal homogeneizador de mundo e de sujeito social. Entretanto, inúmeros outros discursos ressaltam a diversidade e a heterogeneidade, dando voz a pessoas que nos fornecem outros caminhos possíveis para a vida social.

Ora, se na contemporaneidade podemos falar de múltiplos letramentos, que, como vimos, não estão somente em torno do texto impresso, faz-se necessário abrir caminho para esses outros letramentos também na escola. Ao considerar a televisão um educador social de massa capaz de influenciar a vida social, Luke (1997) sugere o estudo desse letramento em sala de aula com o intuito de desenvolver o senso crítico dos alunos. Da mesma forma, Lankshear e Knobel (1997) defendem a leitura, a escrita, a manipulação e a comunicação de textos digitais e sua integração a formas críticas de práticas de letramento. A questão não é apenas inserir esses letramentos midiáticos na escola, mas associá-los ao letramento crítico, para ajudar os alunos a refletirem criticamente sobre os significados produzidos por esses textos da mídia.

Não basta levar os discursos midiáticos para a sala de aula, sem problematizar as questões sociais, culturais e ideológicas que esses textos envolvem. De fato, esses discursos são construídos por relações de poder e investidos de posições ideológicas. 
Por essa razão, é fundamental que se questione o seu próprio conteúdo ideológico - o que Wallace (1998, p. 59) define como "ler nas entrelinhas". Ou seja, essa autora propõe um procedimento metodológico que estimula a leitura crítica, o que envolve o reconhecimento de que a linguagem opera ideologicamente pelas escolhas linguísticas, temáticas e de recursos semióticos dos autores de textos. Nesse sentido, Wallace (Loc. cit.) sugere que se atente para quem disse o quê, para quem, onde, para quê, por quê e como, para que os alunos reflitam criticamente sobre esse contexto de construção de significados e seus efeitos de sentido.

Se a linguagem constrói inteligibilidade sobre o que se entende por sujeito e mundo social, cabe fazer com que os alunos percebam que esses letramentos midiáticos produzem esses sentidos que podem causar efeitos sobre todos nós e nossas visões acerca da vida social. Como esses letramentos estão inseridos em estruturas socioculturais, encontram-se ligados a relações de poder. Dessa forma, integrar letramento midiático e letramento crítico possibilita questionar que grupos sociais são privilegiados, que interesses políticos, culturais e econômicos são atendidos e que formas de sociabilidade são privilegiadas, ignoradas ou desprestigiadas pelos discursos. Desenvolver essa capacidade de se relacionar criticamente com os discursos da mídia pode, então, possibilitar que os alunos entendam que os sentidos atribuídos à vida social não nos são dados, como características inatas, mas, ao contrário, são construídos por meio da própria linguagem, atendendo a crenças, padrões e valores chancelados por determinado grupo social.

Assim sendo, novas demandas de comportamento letrado da contemporaneidade parecem problematizar nossas práticas pedagógicas que, além de priorizarem o texto impresso - especialmente de livros didáticos - parecem ainda privilegiar o modelo de letramento autônomo, desvinculando a língua do contexto social. A linguagem, vista como neutra e objetiva, reduz-se a uma visão sistêmica que exclui todos os matizes sociais, culturais e ideológicos. Como a linguagem não é entendida como prática social, enfatiza-se a dimensão psicológica e individual do letramento. Parece claro que se negligencia aos alunos a noção de que utilizamos a linguagem para agir e fazer coisas no mundo social, produzindo efeitos sobre nós mesmos e sobre nossos interagentes. Em outros termos, ignora-se que a linguagem é utilizada para construir o que entendemos por realidade, bem como nossa própria subjetividade. 


\section{REFLEXÕES FINAIS}

É meu juízo que nossas práticas na escola não estão em sintonia com as visões de linguagem e de letramento respaldadas pela teorização de Bakhtin discutida neste artigo. Ao contrário, creio que nossas práticas pedagógicas parecem operar em consonância com uma perspectiva linguística tradicional. Contudo, as novas demandas impostas pela contemporaneidade parecem pôr em xeque esse referencial ainda norteador da Educação.

Em resumo, Bakhtin propôs uma visão de linguagem como fenômeno social. Ou seja, os significados são produzidos na relação com o(s) outro(s), dentro de um contexto socio-histórico. Assim, a definição dos sentidos pressupõe a existência de embates discursivos (MOITA LOPES, 1996). Como o significado não está na palavra, nossa relação com a leitura e a escrita não se reduz à mera decodificação de símbolos. Ao invés disso, o letramento passa a ser encarado como prática social. Dito de outro modo, construímos sentidos em torno dos textos em práticas discursivas, situadas sociohistoricamente e, portanto, influenciadas por valores, crenças e interesses de um grupo social. Esses significados construídos produzem efeitos sobre nós e sobre nossos interlocutores. Isso significa dizer que, quando nos engajamos em práticas de letramento, produzimos efeitos identitários. Portanto, nossas identidades sociais são construídas discursivamente nas práticas de letramento pelas quais circulamos. A convivência com alteridades nessas práticas realça o caráter intercultural das relações sociais.

Para terminar este artigo, considero que fazer uma escola diferente é possível. E uma das condições mais importantes para que isso aconteça é que os professores sintam-se motivados a sair do senso comum e a incorporar novas práticas em seu fazer pedagógico. O que me parece fundamental é entender que cabe a nós a responsabilidade de propor novos sentidos sobre a realidade e sobre nós mesmos nas práticas discursivas nas quais nos engajamos. Como bem aponta Pennycook (2001), dentro das forças macro da sociedade, nossas microações ainda podem operar mudanças. 


\section{REFERÊNCIAS}

AUROUX, Sylvain. (1998). A filosofia da linguagem. Campinas: Unicamp, p. 403434, Anexo 1.

BAKHTIN, Mikhail. (2003). Estética da criação verbal. Trad. Paulo Bezerra. São Paulo: Martins Fontes.

BAKHTIN, Mikhail (Volochinov). (2004). Marxismo e filosofia da linguagem. São Paulo: Hucitec.

BARROS, Diana. Luz. Pessoa. (1996). Contribuições de Bakhtin às teorias do texto e do discurso. In: CASTRO, Gilberto et al. (Orgs.). Diálogos com Bakhtin. Curitiba: UFPR, p. 21-42.

BLOOME, David. (1983). Reading as a social process. Advances in reading and language research. Syracuse: Research and Language Arts Center - Syracuse University, v. 2, p. 165-195.

BLOOME, David. (1993). Necessary indeterminacy and the microethnography study of reading as a social process. Journal of Research in Reading. New York: Blackwell, v. 16, n. 2, p. 98-111.

BRANDÃO, Helena H. Nagamine. (1997). Escrita, leitura, dialogicidade. In: BRAIT, Beth (Org.). Bakhtin, dialogismo e construção de sentido. Campinas, SP: UNICAMP, p. 281-290.

COPE, B.; KALANTZIS, M. (2000). Introduction: multiliteracies: the beginnings of an Idea. In: Cope, B.; Kalantzis, M. (ed) Multiliteracies, literacy learning and the design of social features. London: Routledge.

FARACO, Carlos Alberto. (2003). Linguagem e diálogo: as ideias linguísticas do Ciclo de Bakhtin. Curitiba: Criar.

FREITAS, Maria Teresa de Assunção. (1995). Vygotsky e Bakhtin: um diálogo. In: Ática, Cap. 6.

Vygotsky e Bakhtin. Psicologia e educação: um intertexto. São Paulo, SP:

(1997). Nos textos de Bakhtin e Vygotsky: um encontro possível. In: BRAIT, Beth (Org.). Bakhtin, dialogismo e construção de sentido. Campinas, SP: UNICAMP, p.311-328.

FRIDMAN, Luis Carlos. (2000). Vertigens pós-modernas. Rio de Janeiro: Relume Dumará.

GREEN. Judith. et al. (1994). Constructing literacy in classrooms: literate action as social accomplishment. In: RUDDELL, Robert B.; RUDDELL, Martha Rapp; SINGER, 
Harry (Eds.). Theoretical models and processes of reading. New York: International Reading Association, p. 124-154.

KLEIMAN, Angela. (1995). Modelos de letramento e as práticas de alfabetização na escola. In: (Ed.). Os significados do letramento. Campinas, SP: Mercado de Letras, Cap. 1, p. 15-61.

KRESS, Gunther. (2003). Literacy in the New Media Age. Londres: Routledge.

LANKSHEAR, Colin; KNOBEL, Michele. (1997). Different worlds? Technologymediated classroom learning and students social practices with new technologies in home and community settings. In: Changing literacies. Buckingham: Open University Press, p. 164-187.

LARROSA, Jorge. (2002). Tecnologias do eu e educação. In: SILVA, Tomaz Tadeu da (Org.). O sujeito da Educação: estudos foucaultianos. Petrópolis, RJ: Vozes, p. 35-86.

LEMKE, Jay L. (1995). Textual politics: discourse and social dynamics. London: Taylor \& Francis.

LÉVY, Pierre. (1995). Cibercultura. São Paulo: Ed. 34.

LUKE, Carmen. (1997). Media literacy and cultural studies. In: MUSPRATT, Sandy; LUKE, Alan; FREEBODY, Peter (Eds.). Constructing critical literacies. Cresskill, NJ: Hampton Press, p. 19-49.

MAYBIN, Janet; MOSS, Gemma. (1993). Talk about texts: reading as a social event. Journal of Research in Reading. New York: Blackwell, v. 16, n. 2, p. 138-147.

MOITA LOPES, Luiz Paulo da. (1996). Interdisciplinaridade e intertextualidade: leitura como prática social. III Seminário da Sociedade Internacional Português Língua Estrangeira. Anais. Niterói: Universidade Federal Fluminense, p. 1-9.

. (2003). A nova ordem mundial, os Parâmetros Curriculares Nacionais e o ensino de inglês no Brasil: a base intelectual para uma ação política. In: BARBARA, Leila; RAMOS, Rosinda de Castro Guerra (Orgs.). Reflexão e ações no ensinoaprendizagem de línguas. Campinas, SP: Mercado de Letras, p. 29-57.

(2005a). Inglês no mundo contemporâneo: ampliando oportunidades sociais por meio da educação. Simpósio de TESOL International Research Foundation (TIRF). São Paulo, p. 1-10.

(2005b). A construção do gênero e do letramento na escola: como um tipo de conhecimento gera o outro. Investigações: Linguística e Teoria Literária. Recife: Departamento de Letras da Universidade Federal de Pernambuco, v. 17, n. 2, p. 47-68.

PENNYCOOK, Alastair. (2001). The Politics of language. In: Critical applied linguistics: a critical introduction. Mahwah, NJ: Lawrence Erlbaum, p. 47-140. 
SEMPRINI, Andréa. (1999). O nó górdio epistemológico. In: Multiculturalismo. Bauru, SP: Ed. da Universidade do Sagrado Coração, p. 81-96.

SOARES, Magda B. (2004). Letramento: um tema em três gêneros. Belo Horizonte: Autêntica.

SPINK, Mary Jane (Org.). (1997). Práticas discursivas e produção de sentidos no cotidiano: aproximações teóricas e metodológicas. São Paulo: Cortez.

STAM, Robert. (2000). Bakhtin: da teoria literária à cultura de massa. Ática, p. 2935 .

VEIGA-NETO, Alfredo. (2002). De geometrias, currículo e diferenças. Educação \& Sociedade. Campinas, SP: Centro de Estudos Educação e Sociedade - CEDES / UNICAMP, ano XXIII, n. 79, p. 163-186.

WALLACE, Catherine. (1998). Critical literacy awareness in the EFL classroom. In: FAIRCLOUGH, Norman (Ed.). Critical language awareness. London: Longman, p. 5973.

\section{A AUTORA}

Ana Paula Loureiro é graduada em licenciatura plena em Letras pela Universidade Federal do Rio de Janeiro (1988) e Mestre em Linguística Aplicada pela Universidade Federal do Rio de Janeiro. Professora de inglês do Colégio Pedro II desde 1995. Coordenadora da equipe de inglês do Colégio Santo Inácio onde leciona desde 2000.

E-mail: aplou@hotmail.com 